\title{
Using modern technology to protect vineyards from hail amid climate change
}

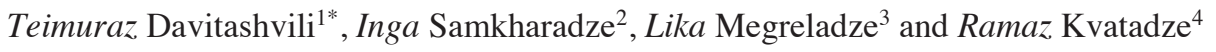 \\ ${ }^{1}$ Iv. Javakhishvili Tbilisi State University, I.Vekua Institute of Applied Mathematics, 0186, 2, University str., Tbilisi, Georgia \\ ${ }^{2}$ Iv. Javakhishvili Tbilisi State University, Faculty of Exact and Natural Sciences, 0143, 1 Chavchavadze ave, Tbilisi, Georgia \\ ${ }^{3}$ National Environmental Agency of Georgia, Hydrometeorological Department, 0112, 150, Aghmashenebeli ave., Tbilisi, Georgia \\ ${ }^{4}$ Georgian Research and Educational Networking Association GRENA, 0108, 4a, Chovelidze str., Tbilisi, Georgia
}

\begin{abstract}
Over the past two decades, Georgia has faced increasingly heavy rainfall, hail and flooding, which especially devastated Kakheti wine region in Southern Georgia, causing severe damage to hundreds of vineyards. Since 2015, 85 anti-hail missile systems have been installed to protect entire Kakheti region, however, for the effective use of a modern anti-hail system, it became necessary to timely forecast extreme weather events of a regional and local scale. Thus, this article aims to develop timely forecasting of strong convection, dangerous precipitation and hail using modern weather forecasting models and radar technologies in Georgia. For this reasons various combinations of the physics parameterization schemes of the WRF-ARW model, the ARL READY system and the data of the modern meteorological radar Meteor $735 \mathrm{CDP} 10$ are used to predict the thermodynamic state of the atmosphere and assess the possible level of development of convective processes. The analysis of the calculated results showed that the variants of the microphysics parametrization schemes of the WRF model lead to significant variability in precipitation forecasts on complex terrain. Meanwhile, the upper-air diagrams of the READY system clearly showed the instability of the atmosphere for the cases discussed. Some results of these calculations are presented and analysed in this paper.
\end{abstract}

\section{Introduction}

Currently, the problem of global climate change is directly linked to growing environmental pollution by anthropogenic waste, the crisis in the field of public health safety (caused by environmental pollution, the outbreak of infectious diseases), the production of highquality food etc. [1]. For instance, it has become apparent that in the context of global and regional climate change, serious threats arise even for conventional and basic food production due to increased rainfall, catastrophic floods, prolonged droughts, growing desertification processes and changed duration of seasons (in mid-latitudes, summers get hotter and winters are colder, the length of spring decreases with decreasing temperature, and only the duration of autumn increases with warm weather) [2]. Outbreaks of climate change, such as increased rainfalls, catastrophic floods, hails, are especially noticeable in regions with heterogeneous topography [2]. Climate change has not bypassed the territory of Georgia, as evidenced by the trend towards an increase in average annual temperature (with average daily minimum temperature and average daily maximum temperature) [2,3]. The geographic location of Georgia and especially the complex relief (about $75 \%$ of the 69,700 sq. $\mathrm{km}$ total land area occupied by mountains and mountain ranges with complex topographic sections) play an important role in formation of 15 local climatic zones in Georgia $[3,4]$. Indeed, Georgia lies between the Black Sea and the Caspian Sea (along the Black Sea eastern coast), to the south of the Main Caucasus Ridge and to the north of the Lesser Caucasus Mountains (the Lesser Caucasus Mountains occupy the southern part of Georgia). These two mountain systems are linked by the Likhi (Surami) mountain range, which is located almost along the meridian and bisects the country into western and eastern parts with different climatic features (see Fig.1).

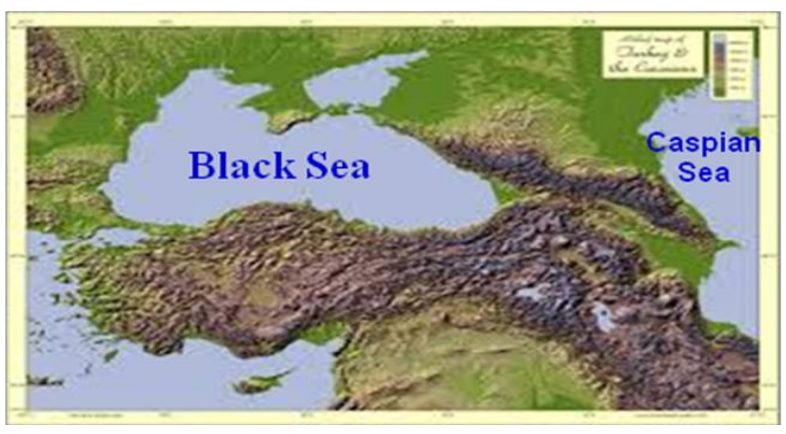

Fig. 1. A physical map of the Caucasus (Georgia)

Generally, the territory of Georgia extends from the subtropical zone of the southeast coast of the Black Sea

\footnotetext{
*Corresponding author: teimuraz.davitashvili@tsu.ge
} 
to the high peaks of the Greater Caucasus and the semideserts of the lowlands in the southeast.

The climate change process and its impact on the environment has become more than ever obvious over the past decade in Georgia. According to statistics of the National Environmental Agency (NEA) of Georgia, the frequency of natural disasters in recent decades has increased significantly, namely heavy rains increased with dramatic consequences, which undoubtedly is associated with climate change [3]. Heavy rains, hail, floods and drought are the main climatological hazards for the country [5-7]. It is reported that floods kills more people, but droughts affect far more number of people and causes more economic damage in Georgia. For example, a severe drought in 2000 affected about 700,000 people and caused damage of $5.6 \%$ of GDP due to its impact on agriculture and hydropower production [8]. The same applies to natural disasters such as landslides, avalanches and tornadoes indicating climate change $[3,6,7]$. During the last four decades the number of natural hazards in comparison to 60th years of the last century has increased about three times and as a consequence economic expenses have increased eight times $[2,9]$.

Within the last decades seasonal changes have also been evident, as the desertification process, which has become apparent in Southeastern parts of Georgia. In addition, climate change on the territory of Georgia is manifested well against the background of accelerated melting of Georgian glaciers, an increase in the number of droughts, showers and hails $[2,4,10]$. Studies on the intensity of the formation of hazard showers, hails and floods against the backdrop of modern climate change in Eastern Georgia were conducted for the period of 19212000. The analysis showed that the frequency of recurrence of hazard floods for the period of 1961-2000 compared to the period of 1921-1960 increased by $150 \%$ in Eastern Georgia [6,8,9]. Among them, extremely heavy rainfall with hail increased by $12 \%$, and there are no reliable methods for prediction these dangerous natural phenomenas even for short periods of time $[3,7]$. Especially over the past two decades, the number of showers with hail (as a result of floods and landslides) has increased in Eastern Georgia [5,10]. Currently, climate change is seen as a serious environmental issue, and also poses an additional risk to political stability in the Caucasus region.

The purpose of this article is to discuss anti-hail operations for the safety of vineyards amid regional climate change in Kakheti region of Georgia. Namely, in 2015 in Kakheti, on an area of 650 thousand hectares, work of counteracting the hail was resumed using a modern anti-hail system. The processes of radar observation of a hail of clouds in Kakheti and missile strikes against them are carried out using modern meteorological radar and rocket installations with remote control from Tbilisi. In order to increase the level of protection against hail, the methodological and technological components of the anti-hail system are constantly being improved. In this article, in addition to preventing hail, anti-hail missiles are proposed to use the ARL READY System, a radar for monitoring dangerous hydrometeorological processes and the WRF model for regional weather forecasting in Kakheti.

\section{Problem statement}

Against the backdrop of the current regional climate changes, heavy rains with hails, often accompanied by floods and landslides (more often than usual in mountainous areas), in most cases led to serious losses of both lives and infrastructures [1,9]. It is obvious that timely forecasting of such events is an important step to avoid or minimize the effects of disasters. Over the past two decades, Georgia has been increasingly confronted with heavy rainfalls, hails and floods, which have especially devastated Kakheti wine region causing serious damage to hundreds of vineyards [9]. Wine production occupies one of the main places in the Georgian agricutlural economy there has been a continuous tradition of winemaking in Georgia for 8,000 years http://www.natenadze.company /history-ofgeorgian-wine.html. By order of the Georgian government in Kakheti, anti-hail rocket launchers (one for every $10 \mathrm{~km}$ ) were installed to protect the entire region [10]. However, for the effective use of anti-hail rocket launchers, the need arose to timely predict extreme weather events of regional and local scale. Therefore, the urgent issue is the timely forecasting of strong convection, hazardous precipitation and hail using modern weather forecasting models and radar technologies in Georgia.

\section{Anti-hail service in Eastern Georgia (Kakheti)}

Eastern Georgia is one of the hail-dangerous parts of the world and therefore, numerous works (theoretical and industrial) have been devoted to the problem of action on hail processes $[10,11]$. Given the significant economic damage caused by hails in Georgia, pilot industrial and production works were carried out to combat hail (Kakheti - 800 thousand hectares, Southern Georgia 400 thousand hectares) on the basis of the Alazani antihail expedition in 1960-1990 [10,12]. It should be noted that crystallization reagents $(\mathrm{AgI}, \mathrm{PbI} 2, \mathrm{NaCl})$ were used in almost all studies, and the positive effects of the Alazani anti-hail system varied between $20-95 \%$ with an average value of $75-85 \%$ [10]. In the Soviet period, along with anti-hail operations, other works were carried out in Georgia, such as artificial precipitation, and the regulation of thunderstorm activity of clouds, using rocket, aviation, artillery and other devices and methods $[11,13]$. In 1989, work against hail were discontinued, and as a result, in subsequent years, damage to the national economy increased significantly [10-13]. It was revealed that the areas beaten by the hail in Kakheti increased over the years after the reduction of anti-hail operations and even became larger than before the start of the anti-hail service $[14,15]$.

Given the importance of anti-hail work, with the support of the Government of Georgia, the active work of the Delta Scientific and Technical Center and the 
cooperation of the Institute of Geophysics and the Institute of Hydrometeorology, the work of the anti- hail service in Kakheti on May 28, 2015 was restored [10]. Protection from hail is being carried out in almost 50 countries of the world (Argentina, Austria, Bulgaria, Canada, China, Bosnia and Herzegovina, Germany, Greece, Macedonia, Moldova, Romania, the Russian Federation, Serbia, Spain, etc.). For example, in China, anti-hail operations are carried out on the territory of 42 million ha, and in the Russian Federation - on the territory of 2.5 million ha $[10,11,16]$. In Kakheti, the effectiveness of anti-hail operations depends on the total aerosol pollution of the atmosphere (optical depth of the aerosol and atmospheric turbidity coefficient, respectively) [10]. Statistical analysis of historical data on precipitation and aerosols showed that aerosols can affect deeper clouds of precipitation in the form of sediment suppression [16]. In particular, the suppression effect is stronger in the mountains than over the plains [5], and the influence of anthropogenic aerosols on convective precipitation may play an important role in summer over Kakheti as well $[6,7]$.

The new Anti-hail system in Kakheti consists of: Contemporary weather radar Meteor 735 CDP10 which is a C-band, dual polarized Doppler radar, generating all the data to forecast hail-producing thunderstorms; Central control station with the automatized fire control system (85 rocket launching sites); the autonomous automated rocket launching device SD-26 and SD-52 and anti-hail rocket (Fig.2); scientific group and the group of the maintenance of radar and rocket guns [10].

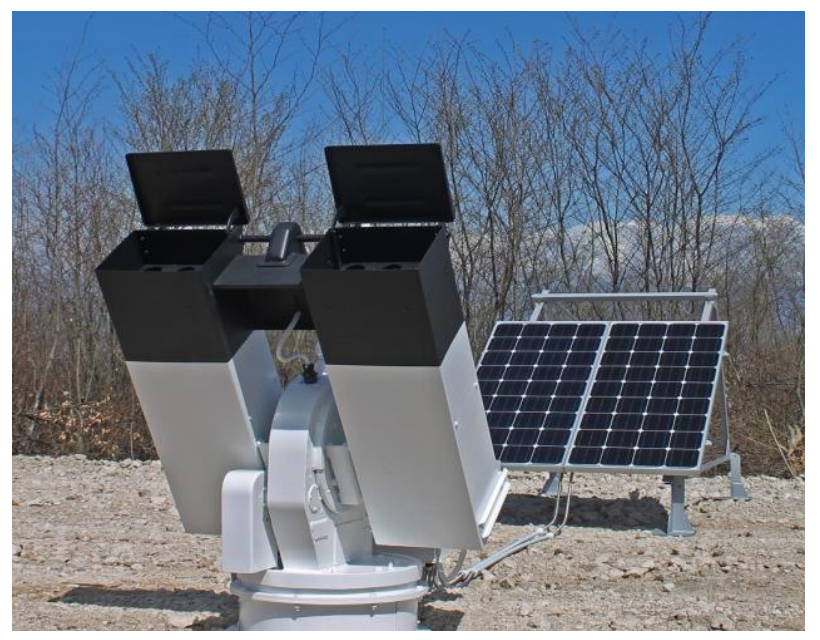

Fig. 2. The automated launching device SD-26.

All information from weather radars and missile launch sites is collected at the central control station in Tbilisi. This information is processed, and then the automated fire control system receives data and sowing zones from special meteorological radar software, determines the optimal launch location, the required number of missiles and sends orders to the appropriate launching devices. The work of the anti-hail service is supported by the scientific organizations - Institute of Geophysics, Institute of Hydrometeorology, etc., which modify the scientific methods of work management [10]. The anti-hail rocket SK-6 manufactured by Macedonia
(Fig. 2) is an unguided 55-mm rocket that carries $40 \mathrm{~g}$ of silver iodide and disperses it at the altitudes of 2.0-4.5 $\mathrm{km}$ for 28-32 seconds [17]. For protection of the entire region of Kakheti, it is necessary to place 85 launch points - one for every $10 \mathrm{~km}$, which is a working ground for the anti-hail rocket. A rocket launcher, a solar battery, grounding and safety systems are installed to the launch pad. The launcher carries 26 anti-hail missiles aimes to shoot at any direction [10, 17]. From 2015 to August 2016, it was possible to use SK-6 anti-hail missiles manufactured by Macedonia. From September 2016 to August 2018, hail-emitting anti-hail missiles "Trayal D 6-B" manufactured by Serbia were used, and from September 2018 to present anti-hail missiles "Loza2" made in Bulgaria are being used [18]. In general, the characteristics of the Loza-2 missiles are slightly better than the Tra-D-6B, but it should be noted that both types of missiles are characterized by insufficient length of the sowing line and about 5000-6000 units are necessary for one year that costs quite expensive to the state [19].

\section{Hail predictions using various physics options of WRF model}

Hail is often associated with the presence of deep convection against a background of complex orography and earth cover. To simulate such smaller scale convective atmospheric processes and its main characteristics it becomes necessary to take into account local features of the relief, atmospheric stratification and the influence of large-scale atmospheric processes. It should be noted that in addition to this, forecasting shortterm, summertime heavy rainfall with hail using numerical models is a difficult task, especially in mountainous regions with complex orography [20-22]. The Weather Research and Forecasting (WRF) models are widely used by many operational services to predict regional weather [23].

In fact, the Advanced Research Weather Research and Forecasting Model (WRF- ARW) is a convenient tool for conducting both research and operational works, as it contains a large number of physics options that can be combined in various ways [24]. Indeed, in the WRFARW model, the main categories of physics parameterization (microphysics, cumulus parameterization, surface physics, planetary boundary layer physics and atmospheric radiation physics) are interconnected through the model state variables (potential temperature, humidity, wind, etc.) and their tendencies $[23,24]$. Among these parameterization scenarios, it is not easy to determine the correct combination which better describes the meteorological phenomenon that dominates the region under study. Our aim is to identify the best combination of parameterizations in the WRF model over the specific study area.

\subsection{WRF model simulation design}

In our study, we have used one-way nested domains centered on the territory of Georgia. The coarser domain 
(resolutions of $6.6 \mathrm{~km}$ ) has a grid of $94 \times 102$ points which covers the South Caucasus region. While the nested inner domain (resolutions $2.2 \mathrm{~km}$ ) has a grid size of $70 \times 70$ points mainly on the territory of Georgia. Both use the 54 vertical levels including 8 levels below $2 \mathrm{~km}$. A time step of 10 seconds was used for the nested domain. The WRF model contains a number of different physics options such as microphysics (MP), cumulus parameterization (CPs), radiation, surface layer, land surface, and planetary boundary layer physics. Microphysics contains a number of MP modules and in our study we have chosen WSM6, Thompson, Purdue Lin, Morrison 2 Moment and Goddard schemes.

Cumulus parameterization schemes are responsible for the sub-grid-scale effects on convective and/or shallow clouds and theoretically valid only for coarser grid sizes [23]. We have chosen Kain-Fritsch, Betts Miller - Janjic and Grell - Devenyi ensemble schemes for our experiments. The planetary boundary layer (PBL) is responsible for vertical sub-grid-scale fluxes due to the eddytransports in whole atmospheric column [23]. Parameterization of the PBL directly influences vertical wind shear, as well as precipitation (hail) evolution [23]. There are number of PBL schemes but according to [23] we have chosen Yonsei University scheme. The landsurface models use atmospheric information from the surface layer scheme, radiative forcing from the radiation scheme, and precipitation forcing from the microphysics and convective schemes. Together with internal information on the land's state variables and landsurface properties, to provide heat and moisture fluxes over land points and sea-ice points [23] were used. We have chosen Noah Land Surface Model. After considering various combinations of MP, CPs, Land surface-physics and planetary boundary layer physics its combination for our experiments are given in the Table 1 .

Table 1. Five set of the WRF parameterizations used in this study.

\begin{tabular}{|l|l|l|l|l|l|}
\hline $\begin{array}{l}\text { WRF } \\
\text { Physics }\end{array}$ & Set1 & Set 2 & Set 3 & Set 4 & Set 5 \\
\hline $\begin{array}{l}\text { Micro } \\
\text { physics }\end{array}$ & $\begin{array}{l}\text { WSM } \\
6\end{array}$ & $\begin{array}{l}\text { Thom } \\
\text { pson }\end{array}$ & $\begin{array}{l}\text { Purdu } \\
\text { e Lin }\end{array}$ & $\begin{array}{l}\text { Morrison } \\
\text { 2-Moment }\end{array}$ & Goddard \\
\hline $\begin{array}{l}\text { Cumulus } \\
\text { Paramete } \\
\text { rization }\end{array}$ & $\begin{array}{l}\text { Kain- } \\
\text { Fritsc }\end{array}$ & $\begin{array}{l}\text { Betts- } \\
\text { Miller } \\
\text { Janjic }\end{array}$ & $\begin{array}{l}\text { Kain- } \\
\text { Fritsc } \\
\text { h }\end{array}$ & $\begin{array}{l}\text { Grell- } \\
\text { Devenyi } \\
\text { ensemble }\end{array}$ & $\begin{array}{l}\text { Kain- } \\
\text { Fritsch }\end{array}$ \\
\hline $\begin{array}{l}\text { Surface } \\
\text { Layer }\end{array}$ & $\begin{array}{l}\text { MM5 } \\
\text { Simil. }\end{array}$ & $\begin{array}{l}\text { MM5 } \\
\text { Simil. }\end{array}$ & $\begin{array}{l}\text { MM5 } \\
\text { Simil }\end{array}$ & $\begin{array}{l}\text { (PX) } \\
\text { Similarity }\end{array}$ & $\begin{array}{l}\text { MM5 } \\
\text { Similarit }\end{array}$ \\
\hline $\begin{array}{l}\text { Planet. } \\
\text { Boundar } \\
\text { y Layer }\end{array}$ & $\begin{array}{l}\text { YSU } \\
\text { PBL }\end{array}$ & $\begin{array}{l}\text { YSU } \\
\text { PBL }\end{array}$ & $\begin{array}{l}\text { YSU } \\
\text { PBL }\end{array}$ & $\begin{array}{l}\text { ACM2 } \\
\text { PBL }\end{array}$ & $\begin{array}{l}\text { YSU } \\
\text { PBL }\end{array}$ \\
\hline $\begin{array}{l}\text { Land- } \\
\text { Surface }\end{array}$ & $\begin{array}{l}\text { Noah } \\
\text { LSM }\end{array}$ & $\begin{array}{l}\text { Noah } \\
\text { LSM }\end{array}$ & $\begin{array}{l}\text { Noah } \\
\text { LSM }\end{array}$ & $\begin{array}{l}\text { Noah } \\
\text { LSM }\end{array}$ & $\begin{array}{l}\text { Noah } \\
\text { LSM }\end{array}$ \\
\hline $\begin{array}{l}\text { Atmosph } \\
\text { eric }\end{array}$ & $\begin{array}{l}\text { RRT } \\
\text { Radiat. }\end{array}$ & $\begin{array}{l}\text { RRT } \\
\text { Mhia }\end{array}$ & $\begin{array}{l}\text { RRT } \\
\text { dhia } \\
\text { dh/Du } \\
\text { dhia }\end{array}$ & $\begin{array}{l}\text { RRTM/D } \\
\text { udhia }\end{array}$ & $\begin{array}{l}\text { RRTM/ } \\
\text { Dudhia }\end{array}$ \\
\hline
\end{tabular}

\section{Results and Discussions}

Four particulate cases of unexpected heavy showers with hail which took place on 5 June, 13-14 June, 22 July and
20-21 August 2015 on the territory of Georgia were investigated. For example weather on June 5, 2015 in Eastern Georgia (Gori, Dusheti, Akhmeta) was extremely bad with showers, hail and flood (Fig.3). At 17:00 cloudy system in the form of atmosphere front moved in Georgia from south-west to the east with velocity $20-25 \mathrm{~m} / \mathrm{s}$. According to weather Radar at 17:45 part of the cloud system reached Tbilisi and the remainder part moved towards the Kakheti region (Akhmeta) where height of the clouds system was about $16 \mathrm{~km}$ and reflecting state-55 $\mathrm{db}$.

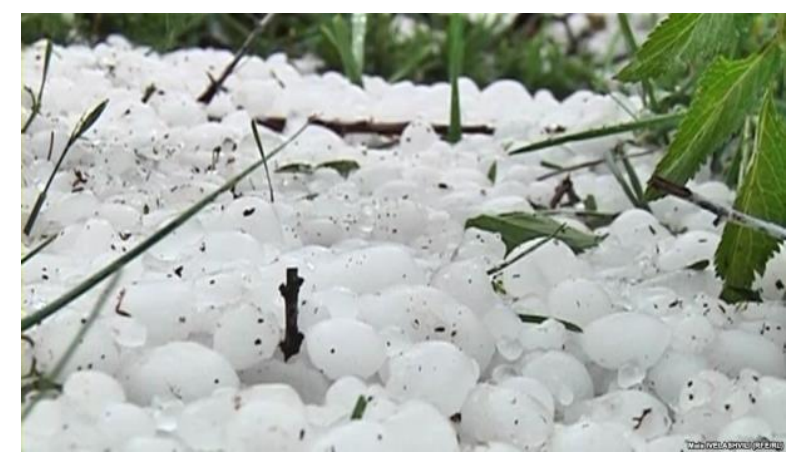

Fig.3 After hail in Kakheti (Akhmeta) on June 52015

Results of calculations performed by Set 1 gave the better results than other combinations and accumulated total precipitations in Gori $\left(41.7^{\circ} \mathrm{N}, 44.6^{\circ} \mathrm{E}\right)$ and hail in Akhmeta $\left(42.0385^{\circ} \mathrm{N}, 45.2068^{\circ}\right.$ E) were predicted satisfactorily (see Fig.4)

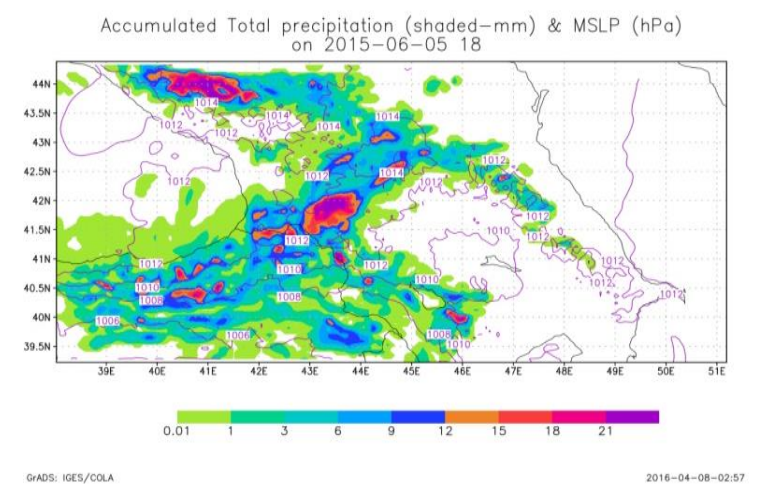

Fig. 4. Accumulated total precipitation ( $2 \mathrm{~h}$ sum) at 18:00 on June 5 simulated by the nested domain with $6.6 \mathrm{~km}$ resolution.

In addition, strong hail and wind destroyed dozens of hectares of vineyards, watermelons and corn gardens in the main wine-growing region Kakheti on July 22, 2015 due to the atmospheric front of occlusion with the processes of internal air mass. At 19:00 a strong cloud system formed over the cities of Akhmet and Telavi $\left(41.9185^{\circ} \mathrm{N}, 45.4777^{\circ} \mathrm{E}\right)$ with a height of $15-16 \mathrm{~km}$ and a reflective state of $60-65 \mathrm{~dB}$. The results of calculations performed using Set 1 and Set 5 gave better results than other combinations. Set 5 with a resolution of $6.6 \mathrm{~km}$ was able to simulate the total precipitation in Dusheti and Akhmet, however, analysis of the results of calculations performed using a fine grid $(2.2 \mathrm{~km})$ improved the quality of the ATP forecast (see Fig. 5). 


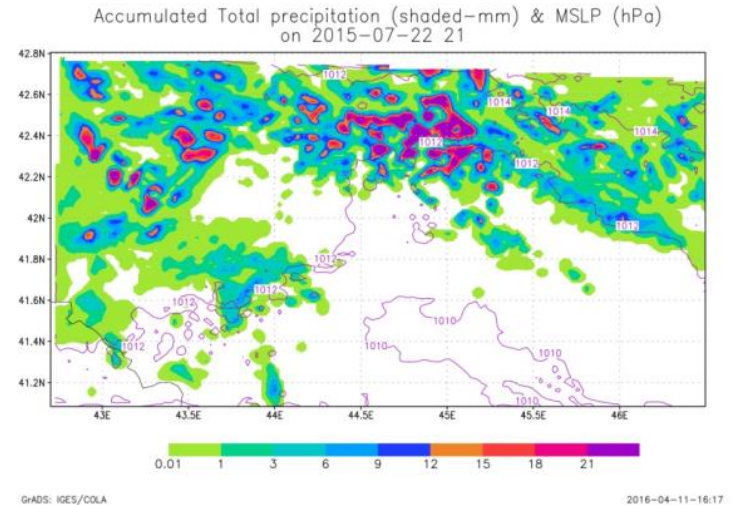

Fig. 5. ATP (2 h sum) forecast using $2.2 \mathrm{~km}$ resolution at 21;00 on $22 / 07 / 2015$ by Set 5

Another case of severe convective events was observed on August 20-21, 2015 in Kakheti. The western atmospheric process prevailed from August 19 to 21 over the territory of Georgia. It was proclaimed on the evening of August 19 in Kakheti. On August 20 heavy rainfall over Kakheti was observed again (see Fig.6). Namely, rain and hail caused by stormy weather lasted half an hour, broke the roofs and even the walls of the houses of Gurjaani, Lagodekhi and Kvareli. About 95\% of the grapes were destroyed by hail in the Lagodekhi and Kvareli districts.

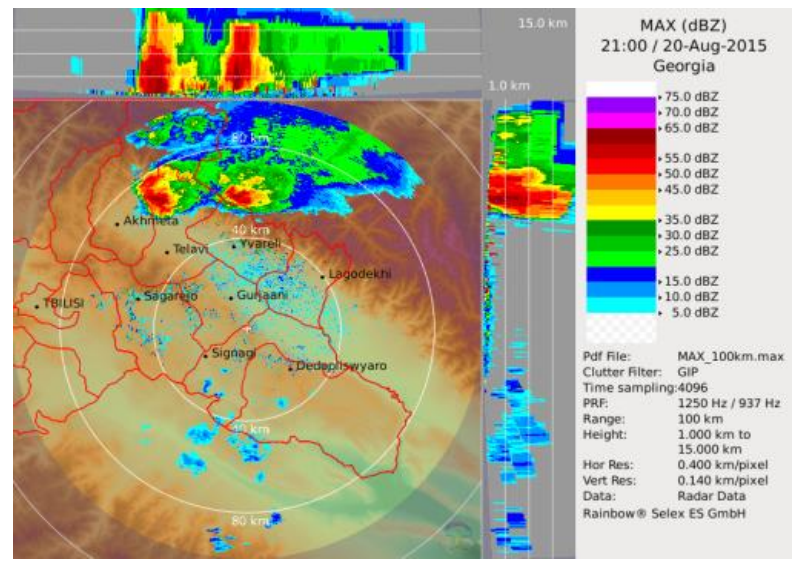

Fig. 6. Meteorological radar Data 21:00 on Aug.20 2015

Comparison of the results of the numerical calculations performed by Set 3 and Set 5 showed that the main characteristics of the ATP were predicted almost equally well, but a detailed analysis and its comparison with the meteorological radar data showed that in this case, Set 3 gave better results than set 5 (see table 1). Thus, comparisons among WRF forecasts allowed verifying that in general the Kain-Fritsch scheme in combination to WSM6, Purdue Lin and Goddard schemes gave better results than others, for western atmosphere processes dominated above the territory of Georgia. Also for evolution and improvement of model skills for different time and spatial scale the verification and assimilation methods should be used for further tuning and fitting of model to local conditions. Also it can be said, that above mentioned model in some combinations of physics options can be successfully used as a basis for WRF
Chem and WRF Climate models above the Caucasus territory.

Currently, the use of the radiosonde is associated with some financial costs, and in some developing countries it is practically not used (among them Georgia). In order to efficiently and timely forecast current atmospheric processes, the Air Resources Laboratory (ARL) of the National Oceanic and Atmospheric Administration (NOAA) has created a Real-Time Environmental Application and Display System (READY, http: // www.ready.noaa.gov). The Air Resources Laboratory (ARL) of the National Oceanic and Atmospheric Administration (NOAA) built aerological charts using an environmental application system and real-time display systems with a horizontal resolution of 0.5 latitude. However the numerical value of the instability power and convective braking power is estimated using the system READY. ARL with a horizontal resolution of 1.0 latitude $(\sim 111 \mathrm{~km}))$. All meteorological forecast data available through READY comes directly from NCEP and includes a wide range of scales. Global Forecast System (GFS) model with horizontal resolutions of 0.5 and $1.0 \_$latitude $(\sim 111$ $\mathrm{km}), 3 \mathrm{~km}$ high resolution fast update model (HRRR) covering the lower 48 states, and NAM Fire Weather Nest jack that moves to a new place when there is a need for detailed meteorological forecast data. The finished ARL NOAA system also has an archive of methodological data, including HRRR, NAM, NAM Data Assimilation System (NDAS), Global Data Assimilation System (GDAS) and NCEP / National Atmospheric Research (NCAR) reanalysis data.

In order to assess the thermodynamic state of the atmosphere for the extreme days discussed in this article, we used the READY System archive [25]. We compared the obtained results to the obtained real data from the Signagi meteorological radar. Aeorological diagrams for discussed cases precisely showed instability of atmosphere on local territory despite the fact that in all four cases we had different levels of instability. These differences corresponded to real meteorological condition of specified day (according to the data of meteorological radar). According to the obtained results it can be stated that under the basis of analysis of forecast aeorological data availabe for specific regions through READY System of ARL of NOAA it is possible to forecast thermodynamic condition of atmosphere. Also evaluation of possible development level of convective processes on local territory together with forecasting methods of forecasting operative office for the weather of Georgia will improve the level of forecasting.

\section{Conclusions}

Currently, heavy rains with hail (often accompanied by floods and landslides) in most cases lead to serious loss of vineyards in many regions of the earth. Therefore, timely forecasting of such strong convective phenomena using modern technologies is an important task. This article aims to develop a forecasting approach using the 
WRF model, ARL READY system and meteorological radar to study the thermodynamic state of the atmosphere in Georgia. The analysis of WRF calculations performed for four cases of heavy showers with hail made it possible to test the best combinations of parametrization schemes for microphysics and cumulus clouds of the WRF-ARW model in the difficult terrain of Georgia. It was found that in cases where the regional WRF model is not able to predict local, shortterm, severe weather convective events [6], the upper-air diagrams of the READY system clearly show the instability of the atmosphere. Hence to improve the safety of vineyards, it is advisable to use in conjunction with the WRF model, the READY system and meteorological radar.

This research was supported by the Shota Rustaveli National Science Foundation Grant FR2017/FR17-548. Also the authors would like to thank Dr. N. Kutaladze and Mr. G. Mikuchadze for putting WRF model at our disposal.

\section{References}

1. IPCC. Climate Change 2007: Synthesis Report. Pachauri, R.K. and A. Reisinger (eds.), Contribution of Working Groups I, II and III to the Fourth Assessment. Report of the Intergovernmental Panel on Climate Change. Geneva, Switzerland. (2007)

2. M. I. Westphal, M. Mehtiyev M. Shvangiradze V. Tonoyan, Regional Climate Change Impacts Study for the South Caucasus Region, 63, (2011)

3. Second National Communication to the United Nations Framework Convention on Climate Change; Ministry of Environment Protection and Natural Resources, Republic of Georgia., www.unfccc.int, (2009)

4. Sh. Javakhishvili. Georgian Climate Description by the Months. Tbilisi., (1988).

5. T. Davitashvili, N., Kutaladze R. Kvatadze et al., Effect of dust aerosols in forming the regional climate of Georgia. Scalable Computing: Practice and Experience, 19 (2), 2018

6. T. Davitashvili, On Some Aspects of Climate Change in Georgia, International Journal of Energy and Environment, 12, (2018)

7. T. Davitashvili. Modelling transportation of desert dust to the South Caucasus using WRF Chem model, E3S Web of Conferences 99, 03011, CADUC 2019, (2019)

8. Third National Report of Georgia on IUNCCD, Tbilisi, (2006)

9. SNCU NFCCE, Georgia, (2009)

10. A.G. Amiranashvili, V.A. Chikhladze, U.V. Dzodzuashvili, N. Ya. Ghlonti, I. P. Sauri, J. of the Georgian Geoph. Soc., Iss. B.18B, (2015)

11. N. Bibilashvili, A. Kartsivadze. The Principal basic and principles of hail processes modification, 4th WMO Scient. Conf. on Weather Modification. WMO/IAMAP Symposium, Honolulu, Hawaii, USA, (1985)
12. A. Amiranashvili, U. Dzodzuashvili, J. Lomtadze, I. Sauri, V. Chikhladze Trans. of Mikheil Nodia institute of Geophysics, v. LXV, Tbilisi, (2015,)

13. A. Amiranashvili, M. Bakhsoliani, N. Begalishvili, et al Trans. of the Inst. of Hydrometeor. of Acad. of. Sc. of Georgia, 108, (2002)

14. O. Varazanashvili, N. Tsereteli, A. Amiranashvili, et al., Natural Hazards, 64, 3,( 2012)

15. A. Amiranashvili, V. Amiranashvili, R. Doreuli, T Khurodze., Yu Kolesnikov. Some Characteristics of Hail Processes in the Kakheti Region of Georgia, Proc.13th Int. Conf. on Clouds and Precipitation, Reno, Nevada, USA, August 14-18, v.2, (2000)

16. X. Guo, D. Fu, X. Li, Z. Hu H. Lei, H Xiao, Y. Hong. Advances in Atmospheric Sciences, 32(2), (2015)

17. http://delta.gov.ge/en/product/anti-hail-system/

18. Rocket "Loza-2" Specification. STROYPROJECT LTD, Bulgaria, (2018)

19. A.G. Amiranashvili, V. A. Chikhladze, U.V. Dzodzuashvili, I. P. Sauri, Sh.O.Telia. J. of the Georgian Geoph. Soc., 22(1), (2019)

20. T. Davitashvili, Z. Khvedelidze, A. Khantadze, K. Tavartkiladze, I.Samkharadze, Trans. of the Instit. of Hydrometeorology 115, (2008)

21. T. Davitashvili, A. Khantadze, On climate, desertification and water pollution problems for the territory of Georgia Netherlands: Springer-Verlag, ,(2008)

22. T. Davitashvili, R. Kvatadze, N. Kutaladze, Weather Prediction Over Caucasus Region Using WRF-ARW Model, MIPRO, 2011, Proceedings of the $34^{\text {th }}$ International Convection, Opatija, Croatia, (2011)

23. W. C. Skamarock, J. B. Klemp, J. Dudhia, D. O. Gill, D. M. Barker, W. Wang, J.G. Powers, A description of the advanced research WRF Version 2. NCAR Tech. Notes. Natl. Cent. for Atmos. Res., Boulder, Colorado. (2005)

24. Z. T. Segele, Lance M. Leslie and Peter J. Lamb, Tellus A, 65, (2013)

25. G. Rolph, Ar. Stein, B. Stunder. Real-time Environmental Applications and Display sytem: READY Environmental Modelling \& Software. 95 (2017) 